\title{
Generation-Side Power Scheduling in a Grid-Connected DC Microgrid
}

\author{
Adriana C. Luna*, Nelson L. Diaz ${ }^{* \dagger}$, Lexuan Meng*, Moisès Graells ${ }^{\ddagger}$, \\ Juan C. Vasquez*, and Josep M. Guerrero* \\ *Dept. Energy Technology, Aalborg University, Aalborg, Denmark, \\ Email: acl@et.aau.dk,nda@et.aau.dk, lme@et.aau.dk, \\ http://www.microgrids.et.aau.dk \\ ${ }^{\dagger}$ Dept. Electronic Engineering, Universidad Distrital, Bogota, Colombia, \\ ${ }^{\ddagger}$ Dept. Chemical Engineering, Universitat Politècnica de Catalunya (UPC), Barcelona, Spain
}

\begin{abstract}
In this paper, a constrained mixed-integer programming model for scheduling the active power supplied by the generation units in storage-based DC microgrids is presented. The optimization problem minimizes operating costs taking into account a two-stage mode operation of the energy storage system so that a more accurate model for optimization of the microgrid operation can be obtained. The model is used in a particular grid-connected DC microgrid that includes two renewable energy sources and an energy storage system which supply a critical load. The results of the scheduling process are including in simulation by establishing a MATLAB/Simulink model of the microgrid and setting several initial conditions of the state of charge of the energy storage system. As a result, we obtain reductions in costs and at the same time guarantee safe levels of state of charge to increase the life-time of the energy storage system.
\end{abstract}

\section{INTRODUCTION}

Microgrids (MG) are energy subsystems integrated by distributed generators (DG), energy storage systems (ESS) and loads, which can operate either in grid connected or islanded mode [1], [2]. In particular, research and development in DC microgrids have increased in renewable energy applications because of the extensive deployment of the energy resources such as photovoltaic (PV) systems and ESS which operate as DC resources [3], [4]. Indeed, DC systems are more suitable for integration of ESS, and alternative power sources since almost all of them are intrinsically DC [5], [6]. Additional advantages that DC microgrid presents over AC microgrids can be found in [6], [7]

DC microgrids require to be managed efficiently to reduce operating cost and avoid damages in the energy storage systems by coordinating optimally the power generation to supply the load according to specific objectives. In fact, ESS are required in order to overcome the power quality problems associated to common changes in the load and the intermittent nature of the energy generated from RES [8].

Optimal control of microgrids is an active field of research [9], [10]. However, in DC microgrids there are very few examples that propose optimal solutions for their management [7]. To illustrate this, in [11] a power balancing strategy is proposed by implemented energy management rules, aiming at reducing grid peak consumption, avoiding undesirable grid power injection, making full use of local PV production. Whereas, in [12] the same problem is solved using the linear programming method known as simplex algorithm. In [13], a deterministic model is used to minimize cost taking into account installation cost and additionally, including a robust approach to assure the scheduling works properly regardless of the disturbances. However, it does not include the changes of the operational modes for charging batteries adequately [8].

Furthermore, mixed integer linear programming optimization models have been used for minimizing total energy cost such in [14] and [15], where the approach is tested for limited state of charge (SoC) of the ESS (50\% to 55\%). In [16], [17], where the model has into account operational modes without having into account the SoC of the batteries. In [18], an optimal control strategy for a DC microgrid is proposed that minimizes the daily total energy costs using additionally demand response. The results show the SoC varying from about $20 \%$ and $100 \%$, but without considering changes in the operational mode of ESS. In [19] an integer linear programming model is formulated to solve the day-ahead optimal scheduling of a DC microgrid by optimizing storage devices and controllable loads paying special attention to the day ahead market and the power allocation of the load.

In this paper, the power scheduling for the generation units of a storage based DC microgrid is proposed by using a constrained mixed-integer programming model. The optimization problem minimizes operating costs having into account a twostage mode operation of the ESS, so that a better model of the microgrid operation can be obtained and, at the same time, it limits the power delivered to the grid while guaranting safe levels of state of charge (SoC) in order to increase the life-time of the ESS unit.

The proposed DC microgrid is tested in a DC microgrid connected to the grid by means of an AC/DC bi-directional converter. The MG is composed of two RES (a wind turbine and a photovoltaic generator) and an ESS that supply a critical load. The grid is assumed as a dispatchable unit and the ESS supports the fluctuations of generation. The references for the power required from the grid and the curtailment of the RES are scheduled in accordance to the optimization program. Meanwhile, primary controllers are responsible of managing the operational modes for a normal operation of the microgrid. A mixed integer programing model is implemented in GAMS to obtain the scheduling data and the results are included in a MATLAB/Simulink model of the DC microgrid for several initial conditions of the state of charge of the ESS. 
Low energy consumption for using the main grid is achieved, while the deep of discharge (DoD) of the ESS is keep above recommended levels [20]. On top of that, the use of the RES is maximized.

The paper is organized as follows. Section II presents the proposed model of energy scheduling. Section III describes the study case. Section IV includes the results. The conclusion is given in Section V.

\section{PROPOSED MODEL OF ENERGY SCHEDULING}

The proposed generation-side scheduling problem for storage-based DC microgrids aims to provide with power references to the converters of the generators in the microgrid (considering the main grid as another power source), as shown in Fig. 1. In general, a DC microgrid consists of $i-1$ generators, $k$ energy storage systems (ESS), $l$ DC loads and the main utility.

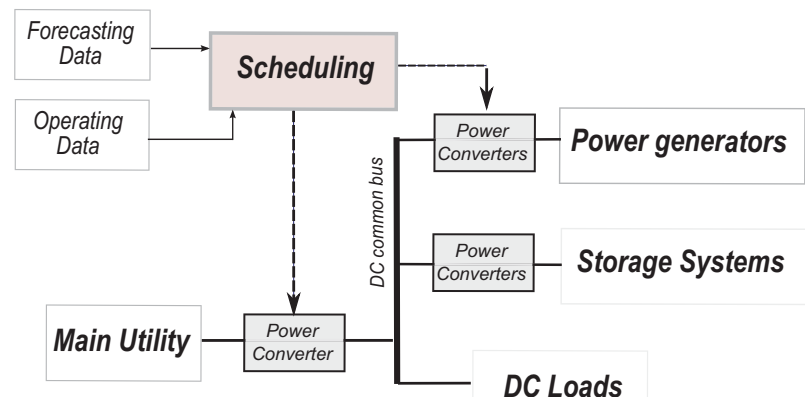

Fig. 1. Generic generation-side scheduling problem for storage-based DC microgrid

The model presented in this paper is a constrained mixedinteger programming that assumes discrete time representation with $t$ as the elementary unit in the range $t=1,2, \ldots, T$. Additionally, the values of active power are considered equal to the average of each time interval.

\section{A. Energy balance}

The balance of supply and demand can be modeled as a linear constraint:

$$
\begin{aligned}
& \sum_{i} \operatorname{Pg}(i, t) * \Delta t+\sum_{k} \operatorname{Pbat}(k, t) * \Delta t= \\
& \sum_{l} P_{L}(l, t) * \Delta t+\operatorname{Plosses}(t), \quad \forall t, i, k, l
\end{aligned}
$$

where $\operatorname{Pg}(i, t)$ is the power supply by the generator $i-t h$ at the time $t, \Delta t$ is the unit time used in the scheduling, $\operatorname{Pbat}(k, t)$ is the power of the $k-t h$ battery at the time $t, P_{L}(n, t)$ is the power of the $l-t h$ load at the time $t$ and Plosses $(t)$ are the power losses that are considered linealized as in [21].

\section{B. Energy Sources}

In general, the power required from the generator $i-t h$ is a positive value bounded by the maximum power value $P g_{\max }(i, t)$ at the time $t$.

$$
0 \leq P g(i, t) \leq P g_{\max }(i, t), \quad \forall t, i
$$

The boundary $P g_{\max }$ is set as function of the time in order to consider cases when the available power is variable.

\section{Energy Storage System}

The $S o C(k, t)$ in the $k-t h$ storage system of the microgrid can be represented in terms of its power as:

$$
\begin{gathered}
S o C(k, t)=S o C(k, t-1)- \\
\varphi_{\text {bat }}(k) *\left[P_{b a t}(k, t) \Delta t\right], \quad \forall k, t
\end{gathered}
$$

where $\varphi_{b a t}(k)$ is a parameter that depends on the technology of the battery. Moreover, $\operatorname{SoC}(k, t-1)$ at $t=1$, is replaced by the given initial condition $\operatorname{SoC}(k, 0)$.

Additionally, the global balance of the SoC is ensured by establishing the condition:

$$
\sum_{t=1}^{T-1} S o C(k, t+1)-S o C(k, t) \geq 0, \quad \forall k
$$

In addition, the $\mathrm{SoC}$ of the $k-t h \mathrm{ESS}$ is bounded as:

$$
S o C_{\min }(k) \leq S o C(k, t) \leq S o C_{\max }(k), \quad \forall k, t
$$

At the same time, the power managed by the $k-t h$ battery can take values in the range:

$$
\operatorname{Pbat}_{\text {min }}(k) \leq \operatorname{Pbat}(k, t) \leq \operatorname{Pbat}_{\text {max }}(k), \quad \forall k, t
$$

Beyond that, the ESS can be operated in operation modes: normal operation or fully-charged (constant control charge). In the first case the battery is able to inject/absorb active power according to the unbalance between generated and consumed power whereas in the second case, it should just takes a small amount of current from the system in order to ensure a constant voltage charge [8], [4]

To implement these cases as a mixed integer problem, the binary variable status $(k, t)$ is defined in the model, as shown in Fig. 2, so that big-M method can be applied. The $k-t h$ battery has a status $(k, t)$, which is equal to 1 when the ESS is fully-charged and zero otherwise. As can be seen, the battery changes its status when the $S o C$ is bigger than the threshold $S o C_{t h}$ and, consequently, the boundaries for $S o C$ and Pbat of the $k-t h$ change.

By considering the above mentioned, the $S o C(k, t)$ at each $t$ bounded in (5) can be rewritten as:

$$
\begin{gathered}
\left(\operatorname{SoC}_{t h}(k)-1\right)-a(k) *(1-\operatorname{status}(k, t)) \leq \\
\operatorname{SoC}(k, t) \leq \operatorname{SoC}_{t h}(k)+b(k) * \operatorname{status}(k, t), \quad \forall k, t
\end{gathered}
$$

where the constants $a(k)$ and $b(k)$ for the $k$-th battery are defined as:

$$
\begin{aligned}
& a(k)=\left(S o C_{t h}(k)-1\right)-S o C_{\min }(k) \\
& b(k)=S o C_{\max }(k)-S o C_{t h}(k)
\end{aligned}
$$

At the same time, having the two-stage operation of the $k-$ th battery into account, the boundaries of its power, presented in (6), can be written as:

$$
\begin{array}{r}
\operatorname{Pbat}_{t h 2}(k)-c(k) *(1-\operatorname{status}(k, t)) \leq(10) \\
\operatorname{Pbat}(k, t) \leq \operatorname{Pbat}_{t h 1}(k)+d *(1-\operatorname{status}(k, t)), \quad \forall k, t
\end{array}
$$



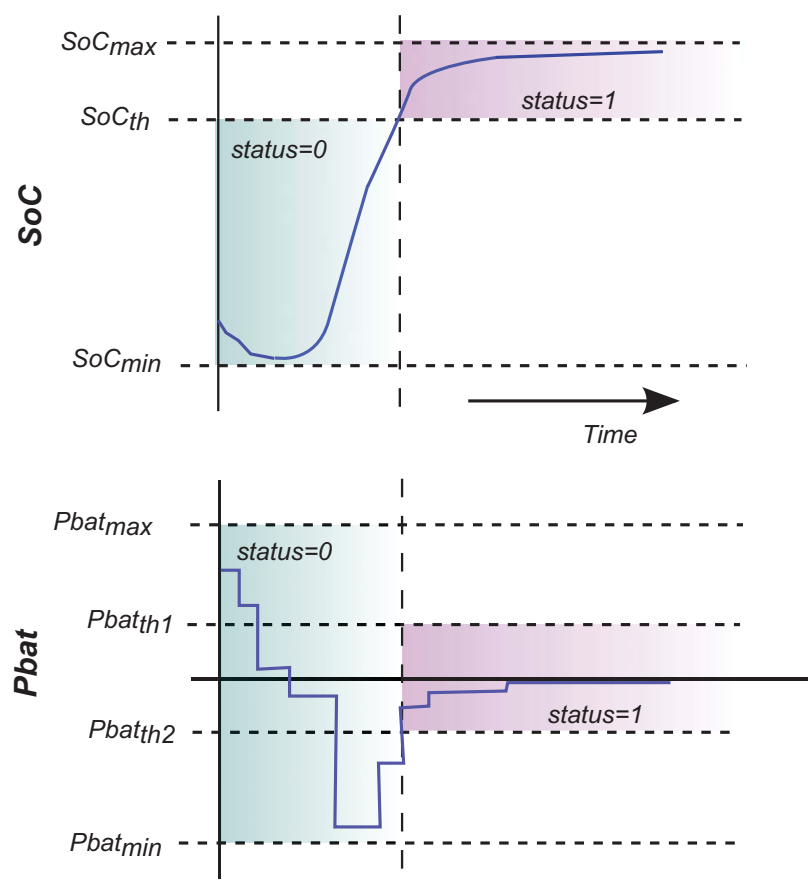

Fig. 2. Two-stages mode operation of the $k-t h$ battery

where $\operatorname{Pbat}_{t h 1}(k)$ and $\operatorname{Pbat}_{t h 2}(k)$ are the boundaries values for the power in the $k-t h$ battery in the fully-charge case as shown in Fig. 2 and the constants $c(k)$ and $d(k)$ are:

$$
\begin{aligned}
c(k) & =\operatorname{Pbat}_{t h 2}(k)-\text { Pbat }_{\text {min }}(k) \\
d(k) & =\operatorname{Pbat}_{\max }(k)-\text { Pbat }_{t h 1}(k)
\end{aligned}
$$

\section{Objective function}

To minimize operating cost, the objective function is composed of two components: the cost to request energy from the $i$ generator and a penalty for not using the renewable sources, and it is defined as:

$$
\begin{gathered}
\text { Totalcost } \left.=\sum_{i} \sum_{t} \operatorname{Pg}(i, t) * \Delta T * C(i, t)\right)+ \\
\sum_{i} \sum_{t}(C \operatorname{Curtail}(i, t) * \Delta T * \xi(i)), \quad \forall i, k, t
\end{gathered}
$$

where Totalcost is the objective function, $C(i, t)$ is the unitary cost of using the $i$ generator at time $t$, and $\xi(i)$ is a shadow cost for no using the available energy of some energy resources. In this case, the non-used energy is proportional to the power:

$$
\text { Curtail }(t, i)=P g_{\max }(i, t)-P g(i, t)
$$

\section{Study CASE}

The study case in which the previous approach has been tested is shown in Fig. 3. The DC microgrid is composed of two RES: a wind turbine (WT) and a photovoltaic generator (PV), an energy storage system (ESS) and a critical load. The DC microgrid is connected to the grid by means of a bidirectional AC/DC converter.

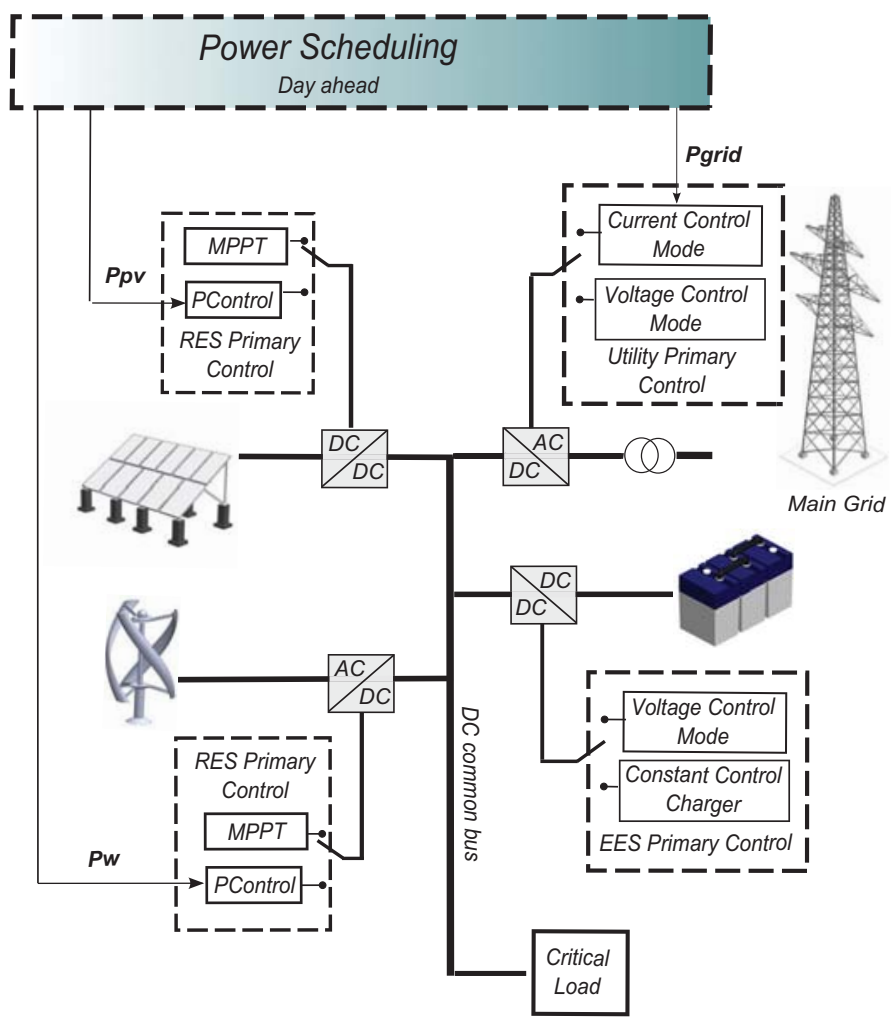

Fig. 3. Study Case DC microgrid

\section{A. Parameters of the DC Microgrid}

The parameters of the DC microgrid are presented in Table I. Considering the structure of the DC microgrid, the number of power sources $n_{g}$ is 3 since the microgrid includes two RES and the grid which is assumed as a dispatchable generation unit. Thus, the sets of the DC microgrid defined in the previous section can be defined as $i=\{P V, W T$, grid $\}, k=1$ and $l=1$.

The parameter of the elementary cost $C(i)$ is considered as constant respect to the time and represents the operational cost in danish kroner (DKK) for using $1 \mathrm{kWh}$. Note that the elementary cost of using the RES is set as $0[\mathrm{DKK} / \mathrm{kWh}]$.

The power losses, $P_{\text {losses }}$, are defined by simulations in the Simulink model of the microgrid before performing the scheduling. Additionally, $P_{\text {gmax }}$ for each RES is a set of real data that is in the range of $0-400 \mathrm{~W}$ which varies at the time. For the grid, this is a fixed value (200W).

Regarding the ESS, the considered storage device is an electric battery whose coefficient $\varphi_{\text {bat }}(k)$ is obtained assuming a nominal voltage value $\operatorname{Vbat}_{n o m}(k)$ for the interval $\Delta t$. The $\varphi_{\text {batk }}$ coefficient is related to the energy capacity and the SoC as is shown in [4].

$$
\varphi_{\text {bat }}(k)=\frac{1}{C_{\text {bat }}(k) * \operatorname{Vbat}_{\text {nom }}(k)}, \quad \forall k
$$

Likewise, $S o C_{\max }(k)$ is selected to allow the battery to be fully charged without overcharging and $S o C_{\min }$ is chosen to limit the depth of discharge (DoD) accordingly with the recommendation of the IEEE1561-2007 standard [20]. 
TABLE I. PARAMETERS USING IN ThE STUdy CASE

\begin{tabular}{|c||c||c|}
\hline Name & Description & Value \\
\hline$T$ & Time of scheduling & $24[\mathrm{~h}]$ \\
$n_{g}$ & Duration of interval & $1[\mathrm{~h}]$ \\
$n_{k}$ & Number of power sources & 3 \\
$C(i)$ & Number of storage systems & 1 \\
$P_{g_{\max }}(i, t)$ & Generation elementary cost & {$[0,0,2]^{\prime}[\mathrm{DKK} / \mathrm{kWh}]$} \\
$P_{L}$ & Power max for generators & $0-400[\mathrm{~W}]$ \\
$P_{l o s s e s}$ & Critical Load & $230[\mathrm{~W}]$ \\
$S_{\max }(k)$ & Power losses & $10[\mathrm{~W}]$ \\
$\operatorname{SoC}_{\min }(k)$ & State of Charge max & $104[\%]$ \\
$\operatorname{SoC}_{t h}(k)$ & State of Charge min & $50[\%]$ \\
$P b a t_{\min }(k)$ & State of Charge threshold & $96[\%]$ \\
$P b a t_{\max }(k)$ & Power of the battery min & $-400[\mathrm{~W}]$ \\
$P b a t_{t h 1}(k)$ & Power of the battery max & $400[\mathrm{~W}]$ \\
$P b a t_{t h 2}(k)$ & Power of the battery th1 & $-80[\mathrm{~W}]$ \\
$\operatorname{SoC}_{\left(k_{0}\right)}$ & Power of the battery th2 & $80[\mathrm{~W}]$ \\
$\varphi_{b a t}(k)$ & Initial Condition & $45-100[\%]$ \\
$\xi(i)$ & SOC coefficient & $20.8[\% / \mathrm{Wh}]$ \\
\hline
\end{tabular}

\section{B. Operation of the Microgrid}

As can be seen in Fig. 3, each converter has its own operational modes managed by primary local controllers which uses voltage bus signaling to perform the changes as is explained in [8]. In particular, for this application all the RES operate under current control mode, by following the reference given by the power optimizer (PControl) or the reference given by the maximum power point tracking (MPPT) algorithm. It is important to say that all the RES will always follow the minimum value between the power reference given by the scheduling process or the MPPT.

Basically, when the ESS is not fully-charged, it operates in voltage control mode (VCM) thus regulating the dc common bus. Meanwhile, the main grid and the RES supply the scheduled power determined by the optimizer.

However, when the ESS is close to be fully-charged, the ESS converter changes its operational mode to constant control charger in which the voltage of the battery is regulated, and consequently, the operational mode of the converter that interconnect the main grid changes its operation mode to VCM, assuming the regulation of the DC common bus [8]. At this time, the RES will follow the scheduled reference in order to avoid overcharging the ESS.

\section{Results}

\section{A. Generation Scheduling}

The optimization problem is implemented by using GAMS to make up the model and then select the solver CPLEX in the program to obtain the scheduling data. The scheduling is performed for different initial conditions of $S o C$. The scheduled power of the grid are presented in Fig. 4.

It should be noted that the power required from the grid is flexible regarding the initial condition of $S o C$. To be more precise, the power required from the grid is higher at the first hours of the day if the initial condition of the $S o C$ is low and at the last hours of the day if $S o C(0)$ is high.

Besides, the SoC of the ESS expected by this model is shown in Fig. 5. As can be seen in Figs. 4 and 5, the

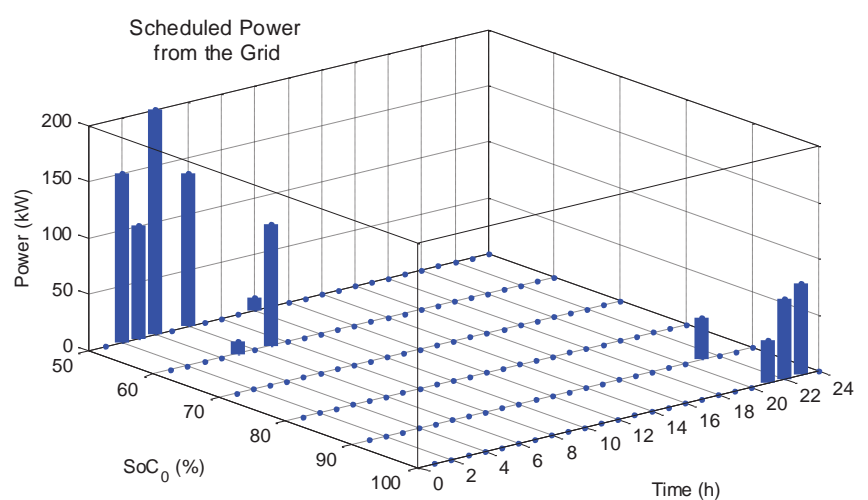

Fig. 4. Power scheduling for the main grid with different initial condition of SoC

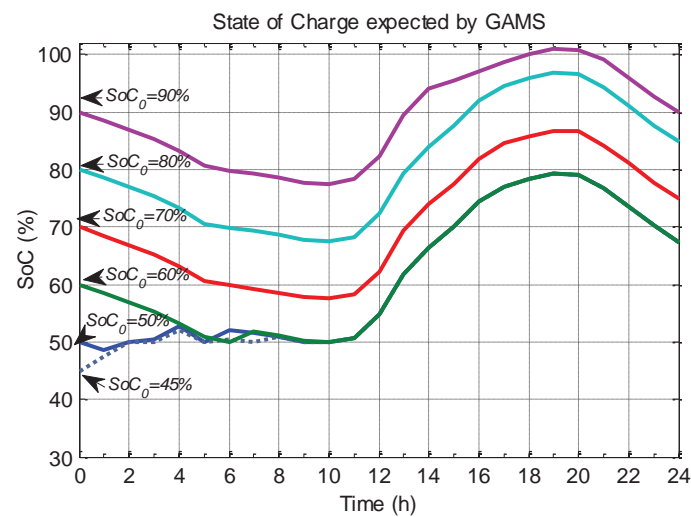

Fig. 5. SoC expected by the scheduling

model does not use the grid unless the initial condition of the $S o C$ is close to the boundaries defined during the scheduling $\left(S o C_{\min }=50 \%\right.$ and $\left.S o C_{\max }=104 \%\right)$. Namely, the power of the grid is used either when the expected $S o C$ during the scheduling time is low, in order to avoid damages of the ESS or it is used to maintain the global balance.

The scheduled power for the RES is shown in Fig. 6 although in the cases with low $S o C(0)(50 \%-80 \%)$ the data are overlapping, thus they are not visible because the energy available can be used in the microgrid during the whole time of scheduling. To emphasize the cases when the curtailment is deployed, they are drawn as dashed-line in the Fig. 6.

As a result, the objective function for the defined initial conditions of $S o C$ are presented in table II.

TABLE II. SCHEDULED OBJECTIVE FUNCTION FOR DIFFERENT INITIAL CONDITIONS OF $\mathrm{SoC}$

\begin{tabular}{|c||c|}
\hline $\mathrm{SoC}(0)(\%)$ & Cost (DKK) \\
\hline 45 & 1.6779 \\
\hline 50 & 1.1979 \\
\hline 60 & 0.2379 \\
\hline 70 & 0 \\
\hline 80 & 0 \\
\hline 90 & 0.6364 \\
\hline 100 & 1.6817 \\
\hline
\end{tabular}

It possible to see that the lowest cost $(0 \mathrm{DKK})$ is obtained 

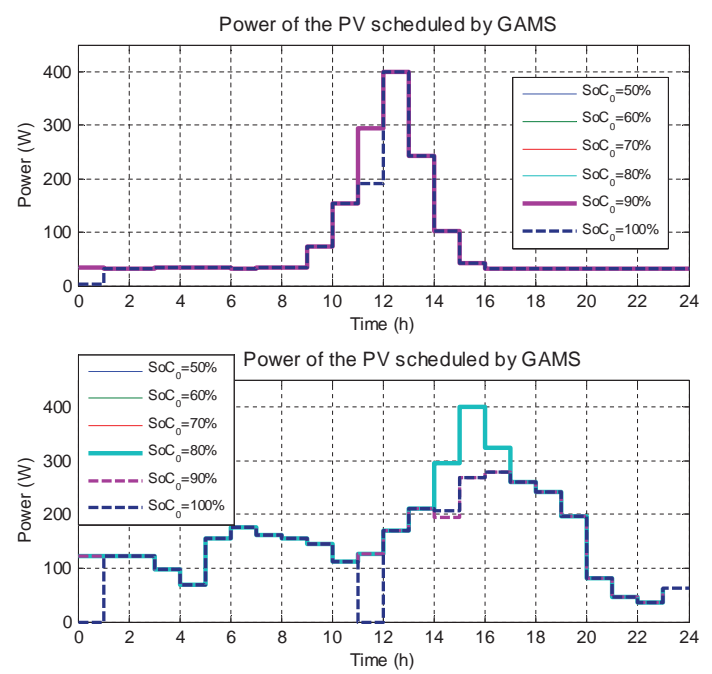

Fig. 6. Power scheduled for RES by GAMS

when the $S o C(0)$ has an intermediate value in the range $\left[S o C_{\min }, S o C_{\max }\right]$ since, the DC microgrid does not need to absorb power from the grid to keep safety the SoC of the ESS, and at the same time, the ESS can store all the energy generated by the RES during the day.

Furthermore, even when the ESS starts the operation with a low amount of energy (lower than $S o C_{\text {min }}$ ), it is not the worst case under the defined objective function. Indeed, the initial condition $S o C(0)=100 \%$ implies to stop using part of the renewable energy during the whole scheduling time and additionally have to use the grid at the end of the day to fulfill the global balance constraint.

\section{B. Simulation Results}

The simulation results of the DC microgrid with and without scheduling are performed by using a MATLAB/Simulink model. The initial conditions of $S o C$ of the storage system $50 \%, 70 \%$ and $90 \%$ are selected in order to observe the behavior of the system under different scenarios.

The power required from the main grid for the selected $S o C(0)$ with and without scheduling is presented in Fig. 7. As can be seen, the active power supplied by the grid without scheduling (dashed lines in Fig. 7) is similar in the three cases of $\operatorname{SoC}(0)$, which is required during the first 10 hours and then during about the last 4 hours (it just varies for $\operatorname{SoC}(0)=90 \%$ when the ESS is fully charged).

By using the previous results, the cost of using the grid in those cases is $1.3471 \mathrm{DKK}$ for $S o C(0)=90 \%$ and 1.1117 DKK for $S o C(0)=50 \%$ and $S o C(0)=70 \%$. Comparing to the expected cost with scheduling presented in Table II, the cost paying for using energy from the main grid is lower by using scheduling unless the $S o C(0)$ is very low $(S o C(0)=$ $\left.S o C_{\min }\right)$.

In addition, the power required from the main grid by the DC microgrid using scheduling (solid lines in Fig. 7) depends on the initial condition of the $S o C$. As expected by scheduling, it is not required power from the grid unless the $S o C(0)$ is very low or very high (close to the limits defined by the scheduler).
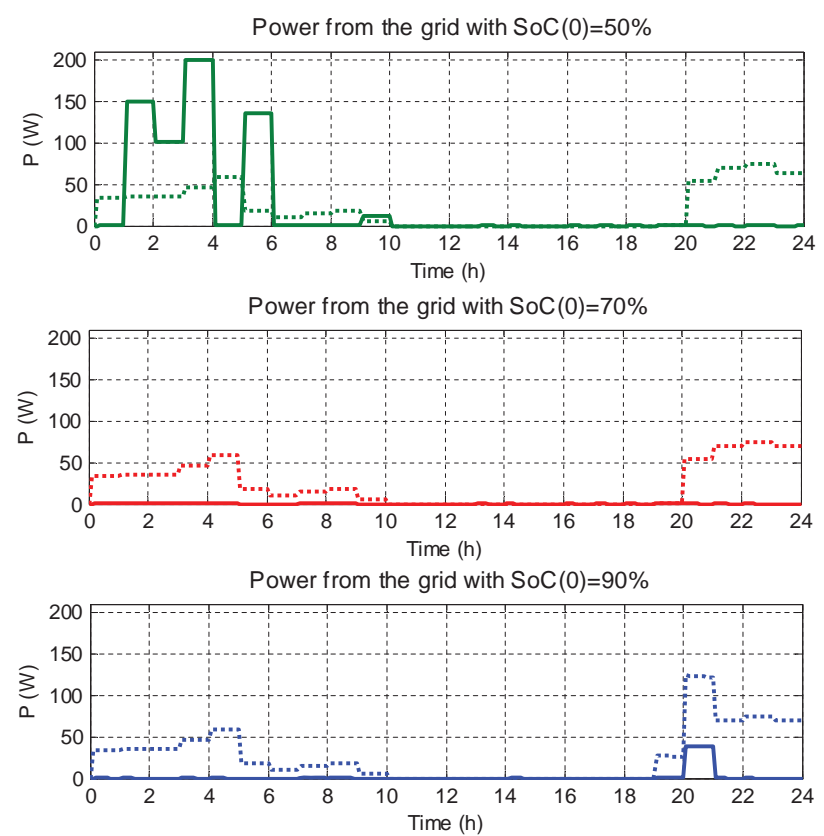

Fig. 7. Power from the grid by simulation. Solid line: with scheduling, dashed line: without scheduling. Top to bottom: with $S o C(0)=50 \%, \operatorname{SoC}(0)=$ $70 \%$ and $S o C(0)=90 \%$

In Fig. 8, the SoC of the ESS for the whole day is presented with (solid line) and without (dashed line) scheduling setting the defined initial conditions of SoC. Comparing to the SoC expected by the scheduling (Fig. 5), it is possible to see that despite the linearity of the scheduling model, the behavior of the SoC can be predicted even when the battery has to change its operation mode.

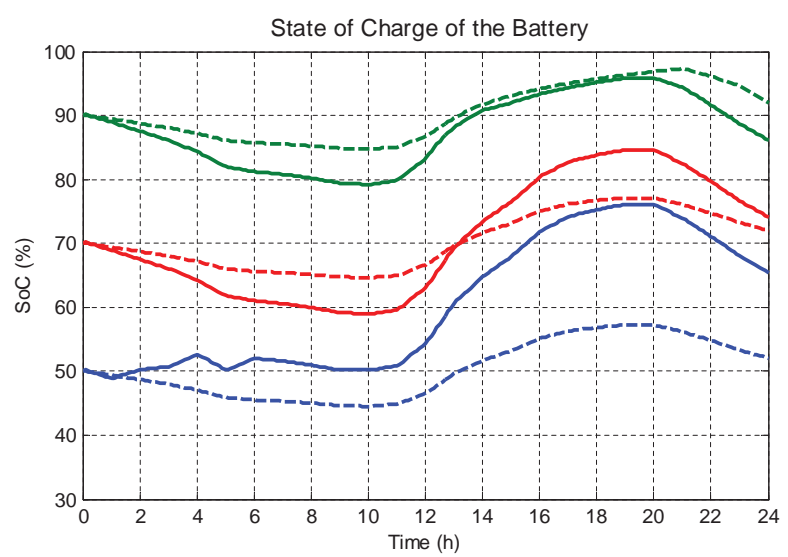

Fig. 8. Simulation of the SoC for different initial conditions with and without scheduling

Without scheduling, the SoC has the same behavior when the ESS does not change fully no matter its initial condition. In contrast, the use of the battery depends on the initial condition of the $S o C$ in the case of setting the scheduled data.

On one hand, the deep of discharge (DoD) of the ESS is always kept above the limits recommended by the standard [20], and consequently the life-time for batteries is ensured. 
To illustrate, when the $\mathrm{SoC}$ is the lowest allowed $(S o C(0)=$ $S o C_{\min }$ that correspond to the blue solid line in Fig. 5), the power of the grid is used in the interval when the power from the RES is not high enough to supply the load. After that, the battery is charged by using the energy of the renewable sources.

On the other hand, when the initial condition of $\mathrm{SoC}$ is high enough to charge fully the ESS, the power given by the renewable energy is curtailed to avoid battery damages.

Furthermore, when the initial condition of SoC is intermediate $(S o C(0)=70 \%)$ and the ESS is not fully charged or discharge until less that $S o C_{\text {min }}$, the power from the grid is not used during the whole day and the battery is charged and discharged according to the availability of the power of the renewable sources.

\section{COnClusion}

The optimization problem of minimizing operating costs has been established and it has been enhanced by having into account the operational modes of the energy storage system of the DC microgrid, in order to improve the performance of the scheduling and the behavior of the system.

Additionally, it is possible to conclude that, despite the linearity and granularity of the mixed integer optimization model, it is suitable for scheduling the active power references fro the power generators and predicts the behavior of the SoC in the ESS.

From the study case, we can observe that in a DC microgrid the main grid can be considered as a dispatchable generator unit since at any case it requires the use of a power converter, and its power can be scheduled in order to minimize the operational cost.

As future work, the optimization problem should be improved by taking into account additional objective as power losses. Additionally, this approach should be implemented in a rolling horizon scheduling to considered updated conditions.

\section{REFERENCES}

[1] J. Vasquez, J. Guerrero, M. Savaghebi, J. Eloy-Garcia, and R. Teodorescu, "Modeling, analysis, and design of stationary-reference-frame droop-controlled parallel three-phase voltage source inverters," Industrial Electronics, IEEE Transactions on, vol. 60, no. 4, pp. 1271-1280, April 2013.

[2] Q. Jiang, M. Xue, and G. Geng, "Energy management of microgrid in grid-connected and stand-alone modes," Power Systems, IEEE Transactions on, vol. 28, no. 3, pp. 3380-3389, Aug 2013.

[3] J. Guerrero, J. Vasquez, J. Matas, L. de Vicua, and M. Castilla, "Hierarchical control of droop-controlled $\{\mathrm{AC}\}$ and $\{\mathrm{DC}\}$ microgrids; a general approach toward standardization," Industrial Electronics, IEEE Transactions on, vol. 58, no. 1, pp. 158-172, Jan 2011.

[4] T. Dragicevic, J. Guerrero, J. Vasquez, and D. Skrlec, "Supervisory control of an adaptive-droop regulated $\{\mathrm{DC}\}$ microgrid with battery management capability," Power Electronics, IEEE Transactions on, vol. 29, no. 2, pp. 695-706, Feb 2014.

[5] A. Kwasinski and C. Onwuchekwa, "Dynamic behavior and stabilization of dc microgrids with instantaneous constant-power loads," Power Electronics, IEEE Transactions on, vol. 26, no. 3, pp. 822-834, March 2011.

[6] E. Hossain, E. Kabalci, R. Bayindir, and R. Perez, "Microgrid testbeds around the world: State of art," Energy Conversion and Management, vol. 86, no. 0, pp. 132 - 153, 2014. [Online]. Available: http://www.sciencedirect.com/science/article/pii/S0196890414004233
[7] E. Planas, J. Andreu, J. I. Grate, I. M. de Alegra, and E. Ibarra, " $\{\mathrm{AC}\}$ and $\{\mathrm{DC}\}$ technology in microgrids: A review," Renewable and Sustainable Energy Reviews, vol. 43, no. 0, pp. 726 - 749, 2015. [Online]. Available: http://www.sciencedirect.com/science/article/pii/S1364032114010065

[8] N. L. Diaz, T. Dragicevic, J. Vasquez, and J. Guerrero, "Intelligent distributed generation and storage units for dc microgrids; a new concep on cooperative control without communications beyond droop control," Smart Grid, IEEE Transactions on, vol. 5, no. 5, pp. 2476-2485, Sept 2014.

[9] M. Iqbal, M. Azam, M. Naeem, A. Khwaja, and A. Anpalagan, "Optimization classification, algorithms and tools for renewable energy: A review," Renewable and Sustainable Energy Reviews, vol. 39, no. 0, pp. 640 - 654, 2014. [Online]. Available: http://www.sciencedirect.com/science/article/pii/S1364032114005723

[10] H. Kanchev, D. Lu, F. Colas, V. Lazarov, and B. Francois, "Energy management and operational planning of a microgrid with a $\{\mathrm{PV}\}$ based active generator for smart grid applications," Industrial Electronics, IEEE Transactions on, vol. 58, no. 10, pp. 4583-4592, Oct 2011.

[11] M. Sechilariu, B. Wang, and F. Locment, "Building-integrated microgrid: Advanced local energy management for forthcoming smart power grid communication," Energy and Buildings, vol. 59, no. 0, pp. 236 - 243, 2013. [Online]. Available: http://www.sciencedirect.com/science/article/pii/S0378778813000029

[12] M. Sechilariu, B. C. Wang, F. Locment, and A. Jouglet, "Dc microgrid power flow optimization by multi-layer supervision control. design and experimental validation," Energy Conversion and Management, vol. 82, no. 0, pp. 1 - 10, 2014. [Online]. Available: http://www.sciencedirect.com/science/article/pii/S0196890414002015

[13] T. Dragicevic, H. Pandzic, D. Skrlec, I. Kuzle, J. Guerrero, and D. Kirschen, "Capacity optimization of renewable energy sources and battery storage in an autonomous telecommunication facility," Sustainable Energy, IEEE Transactions on, vol. 5, no. 4, pp. 1367-1378, Oct 2014.

[14] M. Sechilariu, B. Wang, and F. Locment, "Power management and optimization for isolated dc microgrid," in Power Electronics, Electrical Drives, Automation and Motion (SPEEDAM), 2014 International Symposium on, June 2014, pp. 1284-1289.

[15] M. Sechilariu, B. C. Wang, and F. Locment, "Supervision control for optimal energy cost management in $\{\mathrm{DC}\}$ microgrid: Design and simulation," International Journal of Electrical Power \& Energy Systems, vol. 58, no. 0, pp. 140 - 149, 2014. [Online]. Available: http://www.sciencedirect.com/science/article/pii/S0142061514000313

[16] H. Morais, P. Kadar, M. Cardoso, Z. Vale, and H. Khodr, " $\{$ VPP $\}$ operating in the isolated grid," in Power and Energy Society General Meeting - Conversion and Delivery of Electrical Energy in the 21st Century, 2008 IEEE, July 2008, pp. 1-6.

[17] H. Morais, P. Kdr, P. Faria, Z. A. Vale, and H. Khodr "Optimal scheduling of a renewable micro-grid in an isolated load area using mixed-integer linear programming," Renewable Energy, vol. 35, no. 1, pp. 151 - 156, 2010. [Online]. Available: http://www.sciencedirect.com/science/article/pii/S0960148109001001

[18] A. Bracale, P. Caramia, G. Carpinelli, E. Mancini, and F. Mottola, "Optimal control strategy of a $\{$ DC $\}$ micro grid," International Journal of Electrical Power \& Energy Systems, vol. 67, no. 0, pp. 25 - 38, 2015. [Online]. Available: http://www.sciencedirect.com/science/article/pii/S0142061514006851

[19] G. Carpinelli, A. Bracale, and P. Caramia, "The great project: Integer linear programming-based day-ahead optimal scheduling of a dc microgrid," in Environment and Electrical Engineering (EEEIC), 2013 12th International Conference on, May 2013, pp. 573-578.

[20] "Ieee guide for optimizing the performance and life of lead-acid batteries in remote hybrid power systems," IEEE Std 1561-2007, pp. C1-25, May 2008.

[21] K. Shimomachi, R. Hara, H. Kita, M. Noritake, H. Hoshi, and K. Hirose, "Development of energy management system for dc microgrid for office building:-day ahead operation scheduling considering weather scenarios-," in Power Systems Computation Conference (PSCC), 2014, Aug 2014, pp. 1-6. 